\title{
SOCIAL POLICY EVALUATION: AN EXAMPLE FROM DRINKING AGE LEGISLATION
}

\author{
Audrey L. Begun \\ University of Michigan
}

\begin{abstract}
This article represents an exploration into issues relevant to the application of evaluation methodologies and theories to the social policy arena. A number of evaluation approaches and issues are explored in the context of an illustrative policy example - that of the legislative changes in minimum legal drinking age in the state of Michigan. This effort is directed towards the goal of furthering the solution of social problems through effective involvement of evaluation strategies in social policy development.
\end{abstract}

In the past two decades, there has been an emerging trend towards increased involvement of the social sciences in the social policy arena. While much of this involvement is directed towards the provision of expert testimony and presentation of research data during the early phases of policy planning and development, interest is being directed to the importance of evaluating social policies in such a manner as to improve the implementation of policy and the likclihood of attaining policy objectives (Caporaso \& Roos, 1973; Dolbeare, 1975; Freeman \& Sherwood, 1970; Scioli \& Cook, 1975). A number of principles which have been developed in program evaluation can also be explored for their potential application to the evaluation of social policies. This presentation seeks to identify a number of issues and principles which have proved relevant to the evaluation of social programs and to explore their relevance to the evaluation of social policy. In ad- dition to identifying these issues and principles, a sample policy decision which permits the more concrete illustration of the topics will be discussed. The illustrative case relates to the 1978 legislative changes in minimum legal drinking age in the state of Michigan. Following a brief review of the history behind this decision, a discussion of evaluation principles related to policy will be presented; this discussion will be subdivided in terms of those issues most pertinent to policy analysis and those pertaining to impact assessment. A number of evaluation efforts directed towards assessing the impact of the legislative changes in drinking age requirements will be discussed within this context (Ferreira \& Sicherman, 1978; Ferrence \& Whitehead, 1975; Naor \& Nashold, 1975; Smart \& Fejer, 1976; Smart \& Goodstadt, 1977; Smart \& Schmidt, 1975; Zylman, 1973, 1974c, 1975).

\section{HISTORICAL OVERVIEW OF THE CASE}

On January 1, 1972, the Age of Majority Bill took effect, granting all the rights and responsiblities of adulthood to 18 year olds. Although this bill covered a wide range of subjects, issues, and rights, most of the controversy during its development revolved around the issue of the right to drink alcoholic beverages at age 18 instead of 21. However, by February 13, 1977 The
Ann Arbor News reported that efforts to "boost the teen drinking age" were underway. This movement's supporters contended that lowering the drinking age had been a serious mistake, which was claiming lives on highways and causing problems in the schools.

On one hand, the Michigan Parent-Teacher Association, the Michigan Association of Secondary School

The author is indebted to Dr. Tony Tripodi and Dr. Wilbur Cohen for comments on earlier versions of this article. Requests for reprints should be sent to Audrey L. Begun, University of Michigan, School of Social Work, 1063-F Frieze, Ann Arbor, MI 48109. 
Principles, the Michigan Council on Alcohol Problems (MICAP - reportedly the new name of the older Michigan Temperance Foundation), and various sheriff and policy associations lined up to support the increase in legal drinking age. On the other hand, the liquor dealers and civil rights lobbyists continued to support the 18-year-old drinking age. A number of bills were created, and on December 22, 1978, a Housesponsored bill took effect, raising the legal drinking age to 19. Soon afterwards, on January 1, 1979, Proposal D went into effect (passed by Michigan voters in the
November 1978 clections), making it illegal for persons under the age of 21 to purchase or consume alcoholic beverages in the state of Michigan. During the periods of debate and lobbying which accompanied each proposal, lobbyists and politicians defined a number of policy issues and objectives related to each of the various stances. In addition, statistics and numerous research reports were presented as evidence by members of both sides of the policy debate "to raise or not to raise" the minimum legal drinking age.

\section{EVALUATION ISSUES AND PRINCIPLES}

Rossi (1972) suggests that the evaluation of social policy actually involves two distinct but complementary problems: policy analysis and impact assessment.

\section{Policy Analysis}

Since effective evaluation requires the clear definition of measurable goals and objectives, it is critical that a policy analysis precede the development of an evaluation design. Such an analysis will optimally include a study of the issues dealt with in the policy, the values and belief systems upon which the policy is predicated, expectations of outcome, interactions with other policies, and policy alternatives (Gil, 1976).

Policy analysis is also important in developing an understanding of those factors which affect the validity of an evaluation product. Many social research efforts suffer threats to internal and external validity, and in this regard, policy evaluation is not unique. However, in addition to the "typical" validity threats, policy evaluation efforts are additionally subject to validity threats from political sources (Segall, 1976). The impact of political realities on the policy evaluation effort can be attributed to a tendency described by Campbell wherein "specific reforms are advocated as though they were certain to be successful" (cited in Segall, 1976, p. 22). A corollary, reported by Mushkin (1973), concerns the potential bias resulting from the fact that evaluators are often encouraged to demonstrate "surprising" findings and results. Most typically, the advocate of a social reform or policy change, once committed to that program, is likely to prefer to limit evaluation activities to those areas in which there is considerable control over outcome (e.g., through administrative/financial control over evaluation personnel; control over the specification of objectives, measurement techniques, time frames, target populations, and evaluation sites; or control over conclusions and recommendations presented in evaluation reports). The evaluator's decisions, made in response to these political pressures, have a marked impact on the validity of the evaluation results.
A third major contribution of policy analysis to the evaluation process concerns the issue of dissemination and utilization of the evaluation product. Buchanan and Wholey (1974) have expressed disappointment in the minor impact which evaluation has had on the development of programs. Much of this failure to influence program or policy development can be attributed to inadequate consideration of the decisionmaking processes involved. Too often, evaluators neglect to consider ways in which the evaluation product can be most effectively disseminated, and thereby applied, to policy determination. A detailed policy analysis is likely to provide the evaluator with information essential to making decisions about designing, translating, and disseminating the evaluation product, with the goal of improved utilization by policy-makers during the ongoing phases of policy development.

Information relevant to a brief policy analysis of the Michigan drinking age legislation has been gleaned from a review of news reports from the 1971-1979 period, and from the 1971 report of the Governor's Special Commission on the Age of Majority. The main issue dealt with in the case under study can easily be identified as the restriction of alcohol consumption to those over the age of 21 ; this is not so much a definition of who may drink as it is a definition of who may not.

The analysis of beliefs, values, theories, and expectations related to this policy is a more complex matter. The major values and expectations which have been presented in discussions favoring the decision to raise the legal drinking age include: (1) a belief that outlawing teenage drinking will reduce the rate of traffic accidents involving alcohol and (2) the belief that outlawing teenage drinking will eradicate the disruptive influence of such drinking in the public high schools. The major values and expectations expressed by opponents of the policy include: (1) the belief that such a policy violates the civil rights of 18 to 21 year olds who are otherwise considered as adults; (2) the belief that teens may begin drinking in their cars, instead of in bars or at home, resulting in an increased accident rate rather 
than a decreased rate as predicted by the bill's supporters; and (3) the belief that the law will not be effectively enforced, with the result that those teens who decide to drink will do so, thereby creating a disrespect for the state's legal system.

The heated nature of the debates that arose during the policy development period suggests that several covert issues were involved, in addition to those publicly discussed. One such conflict could involve the temperance belief that alcohol use is inherently evil and that outlawing drinking among teens is one step towards general prohibition. A second covert conflict may be described as a state-wide battle of control versus autonomy between the adults and youth of Michigan. Additional values and objectives may exist, especially where threats to political or financial security are involved (e.g., as in the case of the state's underage bartenders and owners of liquor stores and bars which service the 18 - to 20 -year-old group). The implications of this policy which restricts distribution of alcohol to individuals below the age of 21 represents more than a restriction on resource allocation. It can also be argued that this policy represents a threat to status allocation of individuals who are between the ages of 18 and 21 , since they are adults in all other legal respects. Thus the policy can be viewed as a threat to their status as adults.

An additional aspect of policy analysis concerns the history and development of the policy decision. In this particular example, it is important to know that the right to drink was once denied 18 to 21 year olds in Michigan. After the state's voters had defeated a bill to decrease the legal voting age to 18 , the legislative process had defied the electorate and reduced the age of majority in all aspects to 18 . This action was followed, six years later, by a legislative decision to increase the legal drinking age to 19 . The lobbying in this decision was closely followed by the press in the state and this coverage may have played a role in influencing the state's voters, who - by a large margin - passed a proposal to return the drinking age in the state to 21 . It is likely that many voters were influenced by the arguments offered in support of a one-year increase in the allowable age limit, and decided that if one was good, three years would be better. This pattern of decrcases and increases in drinking age policy provides the policy evaluator with a naturally occurring series of events relevant to the application of time-series evaluation designs.

As a final element in policy analysis, it is important to consider the relationship of the target policy to other policies and policy alternatives. The 1978 Michigan drinking age legislation seems to interact with a number of policies, over and above the obvious example of the 1971 Age of Majority Bill. For example, the policy interacts with state traffic codes which legislate driving under the influence of alcohol, with policies of state and local boards of education, with licensing laws governing liquor services, and with the drinking age policies of nearby communities such as Ohio, Indiana, Wisconsin, and Ontario. During an evaluation of policy impact, an understanding of these inter-policy relationships provides information pertinent to an assessment of policy implementation and enforcement. In addition, a number of policy alternatives (e.g., dropping all age restrictions on alcohol use and allocating funds to treatment and prevention of alcohol abuse; introducing "grandfather clauses" into the bill; altering automobile construction to make it impossible for cars to be operated by users of alcohol) can each be analyzed to shed light on goals, objectives, beliefs and priorities relevant to the evaluation of the target policy.

Even this brief policy analysis provides information pertinent to the development of a unified, broadscoped impact analysis of Michigan's changes in minimum legal drinking age. A number of dependent variables appropriate for study have been identified in the concerns voiced by advocates and protestors of the policy revision. Furthermore, one possible design is suggested by the historical pattern of policy changes (the time-series approach) identified in the policy analysis. Major political forces and attitudes have been identified which serve to sensitize the evaluator to sources of validity threat from the political arena. Finally, the policy analysis cites several routes of dissemination of evaluation products which are likely to enhance utilization potential (e.g., testimony to the legislature, the news media, and commission reports to the governor).

\section{Impact Assessment}

The assessment of a policy's impact involves many of those evaluation activities with which we are most familiar: selection of objectives and criteria, specification of target populations, development of research design and data collection techniques, and development of evaluation reports. Each of these evaluation tasks and related decisions is complex, with a wide range of possible and reasonable responses. Much of the contrast and conflict among evaluation reports stems from a lack of consistency in how various evaluation personnel approached these evaluation tasks. In developing a single, integrated evaluation product, it is useful to consider the possible alternatives, and to explore how various evaluators have approached the task of assessing policy impact.

Objectives and Criteria. The most highly publicized frequently reported effort to evaluate the impact of the drinking age legislation in Michigan has been a project of the University of Michigan Highway Safety Research 
Institute (HSRI). The project, a segment of a more broadly focussed study of highway safety, is designed along the lines of a time-series experiment, with periodic measurements which began well before the policy change. According to HSRI reports in The Ann Arbor News (October 17, 1976) there was a $26 \%$ increase in alcohol-related accidents among teens in 1972 after the drinking age was reduced from 21 to 18 . Various other agencies and interest groups have reported increases in traffic fatalities of $41 \%$ to $58.6 \%$ throughout various time periods since the drinking age was lowered. On the other hand, these reports have been challenged by the executive director of the Michigan Licensed Beverage Association (who was also the secretary-treasurer of the Michigan Commission for the Age of Responsibility - an organization which contested the legality of raising the drinking age). He observed that, between 1966 and 1975, the number of 18- and 19-year-old drivers had increased by $51 \%$, and that the proportion of them involved in accidents had actually decreased from $23 \%$ to $17 \%$. His conclusion is that the decrease in legal drinking age has had no significant impact on the proportions of young drivers involved in traffic accidents.

A major source of confusion and apparent disagreement among these reports on policy impact stems from the use of a variety of impact measurement criteria. Some studies report changes in overall accident rates throughout the state; others report on alcohol-related accidents among teens only; still others report on only those accidents resulting in fatalities (Zylman, 1974b). An additional element of confusion arises in the process of decision-making on the basis of these data; the policy objectives become obscure when one becomes embroiled in debates concerning which of the traffic studies are most relevant. (For example, is it the policy objective to decrease traffic fatalities, traffic accidents in general, alcohol-related accidents in general, or those involving alcohol and teens?)

Identification of Population. In addition to raising issues of criteria and objectives, the evaluations vary in terms of the sample and target populations defined in the reports. For example, some studies include pedestrian and passenger fatalities, while others do not (Zylman, 1974a). A more important observation, however, is that highway safety research is only one form of impact assessment, one which neglects a large portion of the population and a number of policy objectives. Thus, it is important for a broad understanding of policy impact to look at other substrata of the population as well. For example, Smart and Schmidt (1975) present a format for cxploring the drinking age legislation impact for Ontario after the province altered its drinking age policy. They gathered data on alcohol consumption from liquor control statistics, questionnaire responses from high school vice-principals, and ques- tionnaire responses from various student groups. The results from these three sources of data, assessing several objectives, were synthesized into one single report of policy impact.

Design and Data Collection. Smart and Goodstadt (1977) discuss several issues related to evaluation design, but attend most directly to the issue of control groups. In the evaluation of lower drinking age policies, they recommend that two types of control groups be assigned; first, geographical areas in which the drinking age has been lowered (i.e., 18 or 19), and second, those in which the drinking age remains the same (i.e., 21). Because of limited accessibility to data from various states and provinces which might fit these criteria, and possibly because of a lack of control over regional variability in policy implementation and reporting procedures, it is difficult to find studies which have utilized the recommended control group design.

In order to compensate for this difficulty in attaining appropriate control data, Campbell (1979) advocates the use of the interrupted time-series design. Many studies which assess the impact of lowered drinking age in various areas utilize the time-series design; several were in progress at the time of the changes in policy, whereas others were reconstructed on the basis of archival data.

The problem of selecting the "best" design and strategies of data collection is complex. The desirability of each approach differs, depending on the goals and factors identified in the policy analysis. In addition, desirability is strongly affected by the professional value systems of the evaluators themselves. A clear example of a conflict between such value systems appears in a discussion of evaluation methodology by Rossi (1972). In Rossi's (1972) scheme of "most to least desirable" approaches, desirability is contingent on the degree of evaluator control over threats to validity. Hence, a high value is placed on controlled experimental and quasi-experimental designs. On the other hand, Weiss and Rein are cited as strongly advocating the collection of qualitative data through objective observers. This approach is designed to maximize the range, adaptability, and sensitivity of the evaluation effort; by contrast, quasi-experimental designs are criticized as being highly subject to distortion from intervening changes in program, policy, or personnel, as well as being too narrow in focus and for restricting the evaluation "scope of vision." These two points of view regarding the appropriateness of a particular evaluation approach can be expressed as a value conflict arising between those evaluators who are most concerned with issues of range and adaptability in the evaluation effort and those most concerned with experimental validity or control issues.

These issues arise in a review of evaluation reports concering the Michigan drinking age policy. Along with Campbell (1979), Ferreira and Sicherman (1978) 
discuss specific examples of validity threats in timeseries evaluation designs such as the HSRI project. Factors such as the energy crisis which developed in early 1973 and altered the driving habits of many state residents may have had an impact on evaluations which used traffic reports as a data base. A time-series approach, such as the HSRI design, is unable to detect such influences, and is relatively insensitive to various incidental impacts of a policy. In this regard, the somewhat less formal evaluation technique employed by the state's news reporters deserves mention.

These reporters have been responsible for generating a considerable amount of qualitative data concerning the impact of the drinking age policy through interactions with teers, school personnel, and liquor dealers. For example, news reports suggest that the policy change inflicts a financial hardship on bars and liquor dealers located in university communities. Interviews with youth and bartenders suggest that the change in drinking age has not seriously reduced the alcohol consumption of teens - they can drink if they acquire false identification or induce an older friend to purchase the liquor. (In fact, one report described an enterprising college student who ran a business of buying liquor for under-aged students, for a $\$ 5$ fee.) Additionally, one report suggests that the change in legislation might result in a higher traffic mortality rate instead of a lower one as hypothesized - teens were reporting that they were more likely to drink in cars, since they sometimes found it difficult to drink in bars.

The "objective reporting" technique parallels the Weiss and Rein approach of process-oriented qualitative program evaluation. This method generates a descriptive product which assesses, not only policy impact, but policy implementation as well. This technique serves as a valuable supplement to the more controlled studies of specific objectives and outcomes. However, it should be noted that objectivity in reporting, while critical to the effective application of this evaluation approach, can not be presumed in this example. Most reporters live within the communities about which they are reporting, and are likely to exhibit some bias and opinions analogous to those demonstrated in the narrative reports of program "insiders" described by Rossi (1972). In addition, the media is often under pressure to present "surprising" findings, which is one source of evaluator bias discussed by Mushkin (1973).

Reporting. In an article entitled "Semantic Gymnastics in Alcohol-Highway Crash Research and Public Infor- mation," Zylman (1974b) prcsents a series of specific examples of how subtle differences in the way data are reported can result in very different conclusions and interpretations drawn by the reading public. A report may include statistics about traffic fatalities in specific numbers or in terms of percentages; however, the percentages may be derived in a number of ways: they may relate to a portion of all accidents, accidents for a certain age group, or accidents involving alcohol only. The differences in reporting may be interpreted inappropriately by the reader, who is encouraged to focus on percentages without careful consideration of the comparisons being made. (It is interesting to follow a series of interactive articles in the literature which are based, in part, on this issue; see first Zylman, 1974c; followed by Ferrence and Whitehead, 1975; and Zylman, 1975.)

Of greater importance in the reporting of evaluation results is the issue of utilization. Archibald (1968) conducted a number of informal interviews with policy makers and observed that when making policy decisions, they were not likely to use information which they found to be ambiguous or confusing. However, during the policy formulation period, Michigan legislators were inundated with conflicting and unassimilated reports on the impact of earlier policy decisions. Therefore, in order to increase the utilization potential of a policy evaluation project, an overview and integration of results from various related reports would be advisable.

Such a review does suggest several outcomes of the drinking age policy modifications: it seems that an increase in legal drinking age has not significantly prevented teenage drinking, although it has altered drinking-related behaviors such as choosing the setting in which drinking activities occur. Also, the lowering of the legal drinking age does seem to have impacted on rates of traffic accidents involving alcohol use, although the actual extent of impact is not clear because of confusion in data collection and reporting approaches. The policy's impact on the schools has not been clearly documented, as there is considerable variability among reports from school staff (Smart \& Schmidt, 1975). Finally, the news reports suggest a host of incidental impacts of the policy revision including economic stresses, confusion among law enforcement officials concerning enforcement expectations and penalties, and various effects on the attitudes and behaviors of the state's youth.

\section{SUMMARY}

It seems that policy evaluation is a more complex process than is a single program evaluation effort, and is subject to many more political threats to validity.
Because there are so many sources of value conflict among evaluation experts, as well as a wide variety of unpredictable influences on evaluation efforts, it is not 
likely that any one system of evaluating social policies can be designed and utilized effectively. An alternative to finding the "ideal" policy evaluation paradigm involves the integration of various evaluation approaches into a single overview of the specific policy decision. Such an integration of technique can compensate for weaknesses of individual approaches, as well as answer a wide range of impact and implementation questions. Thus an evaluation of Michigan's changes in drinking age policy might consist of a blend of designs and data collection techniques, including the quasi-experimental accident studies; newspaper reports of impact on bars, liquor dealers, schools, youth and families; and comparisons relating Michigan to other communities along a number of social and economic dimensions. Policy analysis provides insight essential to appropriate interpretations of evaluation results, an historical and political context for consideration of evaluation results, an historical and political context for consideration of evaluation results, and a greater understanding of policy objectives. The analysis additionally aids in the development of the evaluation report, and in the design of dissemination and utilization strategies. Finally, an artful integration of these approaches and results would be expected to assist policy makers throughout all stages of policy development, thus engaging the social scientist in truly formative evaluation efforts.

\section{REFERENCES}

ARCHIBALD, K.A. The utilization of social research and policy analysis. Doctoral dissertation, Washington University, 1968.

BUCHANAN, G.N., \& WHOLEY, J.S. Overview of evaluation at the federal level. In J.G. Albert \& M. Kamrass (Eds.), Social experiments and social program evaluation. Cambridge, Mass.: Ballinger, 1974.

CAMPBELL, D.T. Assessing the impact of planned social change. Evaluation and Program Planning, 1979, 2(1), 67-90.

CAPORASO, J.A., \& ROOS, L.L. Quasi-experimental approaches: Testing theory and evaluating policy. Evanston, Ill.: Northwestern University Press, 1973.

DOLBEARE, K.M. (Ed.). Public policy evaluation. Sage Yearbooks in Politics and Public Policy (Vol. 2). Beverly Hills, Calif.: Sage, 1975.

FERREIRA, J., \& SICHERMAN, A. The impact of Massachusetts' reduced drinking age on auto accidents. Accident Analysis and Prevention, 1978, 8(4), 229-239.

FERRENCE, R.G., \& WHITEHEAD, P.C. Fatal crashes among Michigan youth following reduction of the legal drinking age. Journal of Studies on Alcohol, 1975, 36(1), 171-173.

FREEMAN, H.E., \& SHERWOOD, C.C. Social research and social policy (Prentice-Hall series in Social Policy). Englewood Cliffs, N.J.: Prentice-Hall, 1970.

GIL, D.G. Unravelling social policy: Theory, analysis, and political action towards social equality (rev.). Cambridge, Mass.: Schenkman, 1976.

GOVERNOR'S SPECIAL COMMISSION ON THE AGE OF MAJORITY. A report to the Governor, William G. Milliken, Michigan, 1971 .

MUSHKIN, S.J. Evaluations: Use with caution. Evaluation, 1973, I(2), 30-35.

NAOR, E.M., \& NASHOLD, R.D. Teenage driver fatalities following reduction in the legal drinking age. Journal of Safety Research, 1975, 7(2), 74-79.
ROSSI, P.H. Testing for success and failurc in social action. In P.H Rossi \& W. Williams (Eds.), Evaluating social programs: Theory, practice, and politics. New York, N.Y.: Seminar, 1972.

SCIOLI, F.P., \& COOK, T.J. (Eds.). Methodologies for analyzing public policies. Policy studies organization series (Vol. 3). Lexington, Mass.: Lexington Books, 1975.

SEGALL, M.H. Human behavior and public policy: A political psychology. New York, N.Y.: Pergamon Press, 1976.

SMART, R.G., \& FEJER, D. Drug use and driving risk among high school students. Accident Analysis and Prevention, 1976, 8(1), 33-38.

SMART, R.G., \& GOODSTADT, M.S. Effects of reducing the legal alcohol-purchasing age on drinking and drinking problems: A review of empirical studies. Journal of Studies on Alcohol, 1977, 38(7), $1313-1323$.

SMART, R.G., \& SCHMIDT, W. Drinking and problems from drinking after a reduction in the minimum drinking age. British Journal of Addiction, 1975, 70(4), 347-358.

ZYLMAN, R. When it's legal to drink at 18: What should we expect? Journal of Traffic Safety Education, 1973, 20(4), 9-10, 35.

ZYLMAN, R. Drinking and driving after it's legal to drink at 18: Is the problem real? Journal of Alcohol and Drug Education, 1974, 20(1), 48-52. (a)

ZYLMAN, R. Semantic gymnastics in alcohol-highway crash research and public information. Journal of Alcohol and Drug Education, 1974, 19(2), 7-23. (b)

ZYLMAN, R. When it became legal to drink at 18 in Michigan: What happened? Journal of Traffic Safety Education, 1974, 2/(3), 15-16, 38. (c)

ZYLMAN, R. Fatal crashes among Michigan youth following reduction of the legal drinking age: Response. Journal of Studies on Alcohol, 1975, 36(1), 174. 